\title{
Prospective Study of Domestic Accidents of the Child in Brazzaville, Congo
}

\author{
Kambourou Judicaël1,2, Moyen-Engoba',2, Oko Aymar Pierre Gildas',2, Lombet Leticia1, \\ Diall Boubakar'1, Massamba Alphonse ${ }^{3}$, Moyen Georges ${ }^{1,2}$ \\ ${ }^{1}$ Pediatric Intensive Care Unit, University Hospital of Brazzaville, Brazzaville, Congo \\ ${ }^{2}$ Department of Medicine, Faculty of Health Sciences, University Marien NGOUABI, Brazzaville, Congo \\ ${ }^{3}$ Sport Biosciences, Digital Analysis, Computer Science and Applications Laboratory, University Marien \\ NGOUABI, Brazzaville, Congo \\ Email: judycokam@yahoo.fr
}

How to cite this paper: Judicaël, K., Moyen-Engoba, Gildas, O.A.P., Leticia, L., Boubakar, D., Alphonse, M. and Georges, M. (2020) Prospective Study of Domestic Accidents of the Child in Brazzaville, Congo. Open Journal of Pediatrics, 10, 175-184. https://doi.org/10.4236/ojped.2020.101017

Received: December 24, 2019

Accepted: March 3, 2020

Published: March 6, 2020

Copyright $\odot 2020$ by author(s) and Scientific Research Publishing Inc. This work is licensed under the Creative Commons Attribution International License (CC BY 4.0).

http://creativecommons.org/licenses/by/4.0/

\begin{abstract}
Background: Home related accidents have emerged as an important public health issue in pediatrics. However, very few studies have been conducted in sub-saharan countries on domestic accidents among children. The purpose of this study was to determine the hospital frequency of domestic accidents in Brazzaville children, the type of accident, establish etiological factors and mortality. Methods: A total of 173 cases of domestic accidents were collected through a prospective study conducted from 1 January to 31 December 2017 in the pediatric intensive care unit of the University Hospital of Brazzaville. Medical records of children victims of unintentional trauma at home or in its immediate surroundings were collected. The following variables were recorded: the age and sex of the child, the hour, day and month of occurrence of the accident, parental attitudes in the management, and the prognosis (mortality). Results: Domestic accidents accounted for $9.2 \%$ of all admissions. The average age was $28.8 \pm 10.5$ months, a male predominance was noted (sex ratio equal to 1.6). Domestic accidents were found in $57.5 \%$ of children under two years $(p<0.05)$. These children belong with more than 3 children in $63 \%$ of the cases. Accidents were dominated by ingestions (56.1\% of cases), followed by falls (16.2\%), burns (10.9\%) and drug poisoning (9.2\%). They often occurred between $12 \mathrm{pm}$ and $8 \mathrm{pm}$, most often in the yard, the kitchen and the surroundings of the home. Three cases of death (1.53\%) were enrolled including 2 cases of burns. Conclusion: domestic accidents are common in Brazzaville but their frequency is underestimated. Accidental ingestion remains the most frequent type of accident and mortality is high. Control of the causative factors is necessary to undertake effective preventive actions.
\end{abstract}




\section{Keywords}

Domestic Accidents, Burn, Fall, Child, Intoxication

\section{Introduction}

The World Health Organization (WHO) defines domestic accidents as unintentional traumas of everyday life, occurring in the home or its immediate surroundings [1]. They occur mostly in children between one and five years old and much more in the yard and garden [2]. The fall is the predominant mechanism [3]. Domestic accidents cause various injuries such as bruises, wounds and fractures; they can cause disabling sequelae and death [4].

About 830,000 children die each year as a result of unintentional domestic accidents [1] and 12,000 deaths are attributed to domestic accidents in France [5]. In this context, in Europe and the Maghreb, domestic accidents are considered as a real public health problem because of their increasing morbidity and mortality [6] [7]. In developing countries, particularly Sub-Saharan Africa, their incidence is underestimated to the point where some authors speak of it as a forgotten epidemic [8].

In the Congo, pediatric hospital studies report a frequency of $2.7 \%$ to $6.3 \%$; they place accidental intoxication at the forefront of domestic accidents [9] [10] [11]. Ten years after these studies, the extent of domestic accidents of the child is still poorly appreciated. The objective of this study was to describe epidemiological, etiological and prognostic aspects of domestic accidents in Brazzaville.

\section{Patients and Methods}

The prospective and analytical study was based on medical records of children hospitalized between January 1st and December 31st, 2017 in the pediatric intensive care unit (PICU) at the University Hospital of Brazzaville, the only department in charge of the vital distress of the child in Brazzaville. Medical records of children aged one month to 17 years who had been hospitalized in the department during the study period who constituted our study population. Exploitable medical records of children victim of domestic accidents as previously defined [1] were retained. All cases of domestic accidents occurring in children with pre-existing epilepsy and encephalopathy, child abuse and suicide attempts were not included. The same was true for children who presented exclusively trauma of another specialty (neurosurgery, ENT, ophthalmology, stomatology, pediatric surgery).

On the basis of these criteria, 173 cases of child victims of domestic accidents were included in this study.

The data were collected from the medical records and the hospital registries in inquiry forms by the investigator.

For each file, the variables studied were: child's age and sex, sibling rank, 
mother's occupation, day, hour, month, location, etiological circumstances, and type of accident. The treatment administered by the parents before admission as well as the evolution was also studied.

Microsoft Excel 97 and Epi Info software version 3.5.1 were used for data analysis, Pearson's $\mathrm{Chi}^{2}$ test was used to compare qualitative variables. The threshold of significance was set at $p<0.05$.

\section{Results}

\subsection{Frequency of Domestic Accidents}

A total of 173 cases were included out of 1871 hospitalized children, a hospital frequency of $9.2 \%$.

\subsection{Characteristics of the Patients}

Patients were 95 boys (61.6\%) and 78 girls (38.4\%), a sex ratio H/F of 1.6 ( $p<$ $0.05)$; they were aged on average $28.8 \pm 10.5$ months. The characteristics of patients are summarized in Table 1.

The details of domestic accidents are illustrated in Figure 1.

A total of 97 cases of accidental ingestions (56.1\%) were recorded including 82 cases (47.4\%) of oil, 15 cases (8.7\%) of caustic products, 7 cases of foreign bodies (4.7\%); and 16 drug cases (9.2\%). Falls accounted for 40 cases (23.1\%), burns 28 cases (16.1\%), drowning 8 cases (4.6\%).

Table 1. Characteristics of patients.

\begin{tabular}{|c|c|c|c|}
\hline variables & $\begin{array}{c}\mathrm{n} / \text { mediane }(\mathrm{IQR}) \\
\mathrm{N}=173\end{array}$ & $\%$ & Pvalue \\
\hline \multicolumn{4}{|l|}{ Age (mois) } \\
\hline Mediane age & $28.8+/-10.5(7-192)$ & & \\
\hline$<24$ & 99 & 57.5 & \\
\hline$>24$ & 74 & 42.5 & \\
\hline \multicolumn{4}{|l|}{ Sex: } \\
\hline Male & 95 & 61.6 & \\
\hline Female & 78 & 38.4 & $P=0.03$ \\
\hline sex ratio $\mathrm{H} / \mathrm{F}$ & 1.6 & & \\
\hline Mediane size of siblings & $4(3-8)$ & & \\
\hline \multicolumn{4}{|l|}{ Sibling rank: } \\
\hline$>3$ & 109 & 63.0 & \\
\hline$<3$ & 64 & 37 & \\
\hline \multicolumn{4}{|l|}{ Mother's profession: } \\
\hline No occupation & 56 & 32.3 & \\
\hline Saleswoman & 50 & 28.7 & \\
\hline Official & 46 & 26.7 & $P=0.06$ \\
\hline Student & 21 & 12.3 & \\
\hline
\end{tabular}




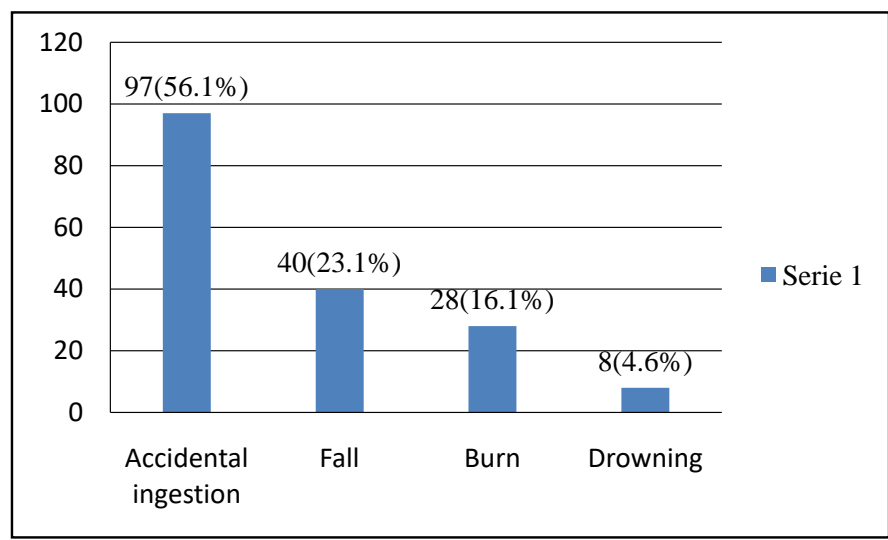

Figure 1. Types of home accidents.

\subsection{Hours and Place of Occurrence of Domestic Accidents}

Accidents occurred between $12 \mathrm{pm}$ and $8 \mathrm{pm}$ in 142 cases $(82.2 \%, p<0.01)$, between 8 am and $12 \mathrm{pm}$ in 21 cases (12.3\%) and beyond $8 \mathrm{pm}$ in 10 cases (5.5\%). Domestic accidents occur every day of the week with peaks on Fridays (20 cases) and on Saturdays ( 25 cases). The months of July ( 40 cases) and August (14 cases) were the peak months for domestic accidents. These months correspond to long school holidays in Congo.

Figure 2 shows the distribution of domestic accidents by place of occurrence.

The domestic accident occurred most often during children's fun in the yard in 80 cases (46.5\%), during households in the kitchen in 42 cases (24.6\%). In 12 cases $(16.4 \%)$, this was the third accident.

\subsection{Treatment Administered by Parents and Evolution}

Treatment was administered by the parents before hospitalization in 66 cases (38.3\%); these were liquid milk in 30 cases (17.3\%), palm oil in 20 cases (11.5\%), herbal tea in 16 cases $(9.2 \%)$. The treatment was associated in each case with an attempt to provoke vomiting.

\subsection{Prognostic Aspects}

Three cases of death were identified, $1.53 \%$. The deaths concerned burns in two cases and drowning in one case. The deceased patients were, on average, six years old; the death occurred on average two days after the occurrence of the domestic accident.

\section{Discussion}

We conducted a monocentric study with the objective to describe epidemiological, etiological and therapeutic aspects before hospital admission and the prognosis of the domestic accidents of the Congolese child. With a frequency of $9.2 \%$ resulting from a collection of 173 files, the results obtained cannot be extrapolated to the national level. In France, the health monitoring institute has set up a permanent survey on everyday accidents, of which domestic accidents account 


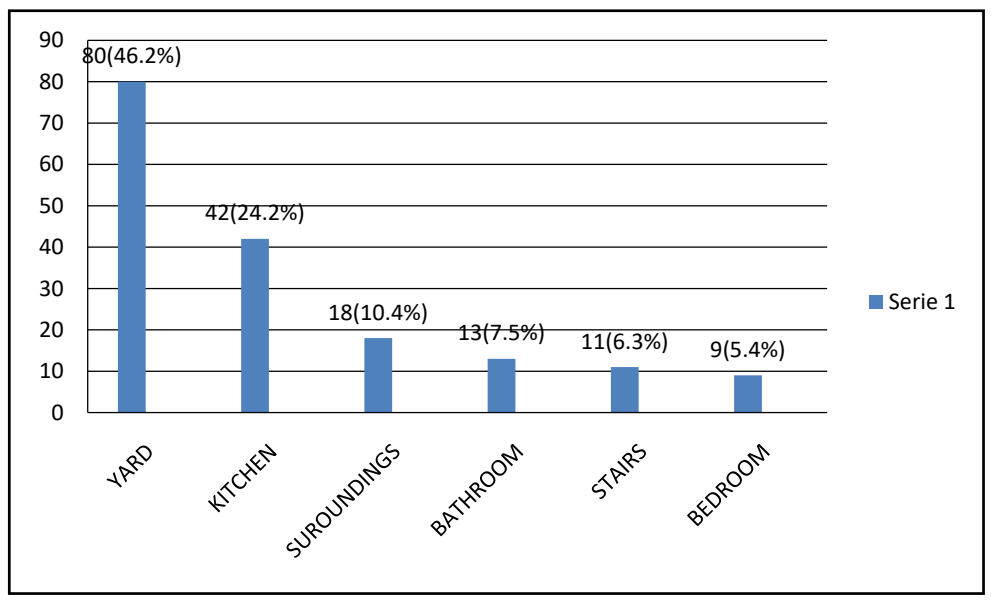

Figure 2. Distribution of domestic accidents according to place of occurrence.

for half of the cases each year. According to 2012 estimates, 56,168 children under the age of 15 were victimday-to-day accidents; in infants less than one year, $80 \%$ of these events occurred at home [12]. The prospective study of Mohamed et al. [13] in Dakar recorded 555 cases from November 2009 to December 2010, representing $28.8 \%$ of all consultations and $16 \%$ of hospitalizations in the emergency unit of the surgery department of the University Hospital Dantec. Ben Hamida et al. [14] reported in an urban area of the Grand Tunis an annual prevalence of $14.7 \%$ among three-year-old children.

Our study finds a male predominance, as in most studies in children [15] and in a previous Congolese study of Mabiala Babela [9] in Brazzaville. This could be explained by the fact that bays are more engaged in leisure activities than girls in addition to their physical and temperamental differences predisposing them to more frequent accidents [16]. This aspect may also be related to the fact that in the Congolese culture girls spend more time on chores than boys.

In addition, our results revealed that domestic accidents occurred more often in children under five (57.5\% less than two years in our series). Our results are similar to findings in the literature [17] [18] [19]. Our observations can be explained by the fact that children of this age spend more time at home compared to older children. With longer exposure to the hazards of the home, children under five are more often victims of domestic accidents.

In our study, most accidents occur in the yard (46.5\% of cases), followed by the kitchen. Similarly, a French investigation reports the bedroom, the stairs, the kitchen then the yard as the common place of occurrence of domestic accidents [5]. In Congo, due to parents' modest incomes estimated at less than USD 200 per month, children share the same bedroom with 3 - 4 siblings, hence the occurrence of falls from a bed although at a lower frequency (4 cases out of 173). The Distribution of domestic accidents according to place of occurrence varies from one study to another. Meanwhile, compared with other African studies, our results have in common the yard as the most common place of occurrence of domestic accidents. 
In our series, the majority of domestic accidents occurred between $12 \mathrm{pm}$ (class end time in public schools in Congo) and $8 \mathrm{pm}$ in $82.2 \%$ of cases ( $p<$ 0.01 ). It is worth noting that in Congo pupils usually attend school from 7 am to $12 \mathrm{pm}$ and a completely different group attends in the afternoon (12 pm to 5 $\mathrm{pm}$ ); This is due to high enrollment rates and plethoric class sizes for low and middle income households (20 USD the year versus 250 USD in private schools). Thus, home, children engage in activities of play or sport. This observation is made by other authors. According to Thélot [3], the chronology of domestic accidents during the day peaks between $4 \mathrm{pm}$ and $7 \mathrm{pm}$.

Regarding the day of occurrence in our series, domestic accidents occurred every day of the week with peaks on Fridays (11.6\% of cases) and Saturdays (14.4\%). Reinberg et al. [20], Carter and Jones [21] note that there is no significant change in the number of accidents by day of the week. On the other hand, at Nordberg [22] domestic accidents occurred much more on working days than on weekends, an observation contradicting our findings. Ategbo et al. [17] in Gabon have made the same observation. According to them, most parents become distressed and exhausted over the weekend and spend less time supervising their children. Children are often left alone or in the care of other children.

In other studies [1] [23], seasonal variations have been observed. In the United States of America, between 1992 and 1999, the highest numbers were recorded during the spring (April to June) and lowest in autumn (October to December) [1]. In our study, accidents occurred more in July and August (31.2\% of cases), the period of long school holidays that corresponds to summer in Western countries. This is in line with that of Mohamed et al. [13] who also note a predominance of cases in July, but also in December and April.

Accidental ingestions in our study constitute the main mechanism of domestic accidents (56.1\% of cases), followed by falls ( $16.2 \%$ of cases), burns ( $10.9 \%$ of cases) and drug poisoning (9.1\%)., 2\%). The accidental ingestions in the study of Mabiala Babela et al. [9], also occupy the first place with a frequency of $63 \%$. This frequency was $65.1 \%$ in the study of Mbika et al. [10]. In developed countries, trauma is the first accidental mechanism [24]. They represent in the study of Lavaud and Chaoukri [25], 95\% of domestic accidents in children. The poisoning with kerosene represented in our series $47.4 \%$. This predominance is explained not only by the fact that kerosene is widely used in Brazzaville for cooking and lighting, given that only $12.5 \%$ of households in Brazzaville benefit from electricity according to the data according to the African Health Observatory of the WHO [26]. Moreover, most domestic accidents occur in families living with modest socio-economic conditions. In addition, there is a link between socio-economic status and housing conditions [27]. The same findings have been reported by other African authors [17] [28]. In most households in Brazzaville, this fuel is packaged in the same containers as drinking water, especially in plastic bottles. The implementation of this procedure is confusing for young children when they want to quench a thirst. However, the frequency of accidental use of toxics differs from one region to another and according to socio-economic ac- 
tivities; thus caustic products are incriminated in $8.7 \%$ of cases of accidental poisoning in our series. Meanwhile, in Europe [29] [30] [31], drugs were most often incriminated against $9.2 \%$ in our study (fourth rank of domestic accidents). In our series, falls are the second most common mechanism of domestic accidents with $16.2 \%$ of cases. This can be explained by the fact that play (jumping and running) is the main leisure activity of children at home. Besides, the child of less than 5 years is in full psychomotor development with the discovery of the environment, the conquest of the autonomy associated with a motor incoordination, the explorations and the new explorations, the will of the discovery of the world with an almost complete dependence of the entourage to appreciate the danger.

Burns, with $10.9 \%$ of cases, are the third most common household accidents in children. These observations are consistent with other studies [32] [33] [34]. In developing countries, burns are a real public health problem, all the more serious as mortality is higher here than elsewhere [35]. This can be explained by the fact that in the infant any burn surface are greater than $10 \%$ can cause a severe hypovolemia if the contributions hydrolytic electrolytes are not adapted. The high incidence of these burns in the infant in our study could be explained by the absence of adequate kitchen in the majority of the households.

Moreover, the frequency of $4.7 \%$ of accidental ingestion of foreign bodies ( 3 cases of coins 2 cases of almonds, 1 case of nuts, 1 case of pearl,) is due to the poor monitoring of the children under the age of five by parents and relatives in terms of foods or items that may be accidentally put in the mouth. Indeed, such accidents often occur between the age of acquisition of a manual grip and that of structured chewing, i.e. between one year and four years. This observation is similar to other studies [9] [17] [36] with a frequency ranging from $2 \%$ to $11 \%$ of the total of the domestic accidents of the child; Meanwhile, the coins are the most recovered.

Regarding the treatments administered by the parents before hospital admission, they are aberrated (liquid milk, palm oil, herbal tea, provoked vomiting).

Finally, mortality is $1.53 \%(\mathrm{n}=3)$ in our series. In a study conducted by Mabiala-Babela et al. [9] on accidental pathology of the infant, the death rate was $1.26 \%$ ( 4 deaths out of 317 cases), similar to our study. Our rate is significantly lower than those reported in the literature, where road accidents, drownings, falls and poisonings account for $60 \%$ of fatal injuries in children [3]. And the trauma by fall, likely to be the most dangerous, is the cranioencephalic traumas; these mechanisms were not found in our study.

\section{Conclusion}

Domestic accidents in children in Brazzaville are frequent and often occur in the yard. The ingestion of kerosene and the burn are incriminated in the majority of fatal outcomes. Given the occurrence of traumatic risks in our context, parents need to be better educated in integrated care centers, preschools with more practical recommendations on home security. 


\section{Conflicts of Interest}

The authors do not declare any conflict of interest.

\section{References}

[1] Organisation Mondiale de la Santé (2017) Rapport trimestriel des statistiques sanitaires mondiales. OMS, Genève.

[2] Peden, M. (2009) World Report on Child Injury Prevention calls for Evidence-Based Interventions. International Journal of Injury Control and Safety Promotion, 16, 57-58. https://doi.org/10.1080/17457300802532990

[3] Thélot, B. (2008) Epidemiology of the Injuries among Children and Teenagers. Archives de Pédiatrie, 15, 758-760. https://doi.org/10.1016/S0929-693X(08)71901-8

[4] Thélot, B. (2010) Epidémiologie des accidents de la vie courante chez l'enfant. Archives de Pédiatrie, 17, 704-705. https://doi.org/10.1016/S0929-693X(10)70069-5

[5] Réseau EPAC (2003) Thélot, B. Institut de veille sanitaire, département maladies chroniques et traumatismes. http://www.invs.sante.fr/publications/2006/epac/epac-fro.pdf

[6] Lavaud, J. (2002) Accidents de l'enfant. EMC-AKOS. Encyclopédie Pratique de Médecine, 8-0940, 19 p.

[7] Maaloul, I., Kmihas, S., Yaich, S., Thouraya, K., Damak, J., Aloulou, H. and Hachicha, M. (2019) Epidémiologie des accidents domestiques de l'enfant: Expérience d'un service de pédiatrie générale du sud tunisien. The Pan African Medical Journal, 33, 108. https://doi.org/10.11604/pamj.2019.33.108.12022

[8] Institut National de Santé Publique (2000) Les accidents domestiques chez l'enfant. Résultats de l'enquête. http://www.santemaghreb.com

[9] Mabiala-Babela, J.-R., Pandzou, N.S. and Moyen, G.-M. (2010) La pathologie accidentelle du nourrisson aux urgences pédiatriques du CHU de Brazzaville (Congo). Journal de Pédiatrie et de Puériculture, 23, 185-190. https://doi.org/10.1016/j.jpp.2010.04.002

[10] Mbika-Cardorelle, A., Okoko, A.R., Ibala, R. and Moyen, G. (2003) Epidémiologie des accidents de l'enfant au CHU de Brazzaville Archives de Pédiatrie, 10, 648-657. https://doi.org/10.1016/S0929-693X(03)00296-3

[11] Atanda, H.L., Porte, J., Bon, J.C., Rodier, J., Moyen, G.M. and Nkoua, J.L. (1992) Ingestion accidentelles de produits toxiques chez l'enfant. A propos de $308 \mathrm{cas}$ observés au centre médico-social ELF Congo, Pointe-Noire. Médecine d Afrique Noire, 39, 107-109.

[12] Institut de Veille Sanitaire (2012) Enquête permanente sur les accidents de la vie courante. Résultat.

[13] Mohamed, A.S., Omid, A., Faye Fall, A.L., Mbaye, P.A., Seck, N.F., Ndour, O., Ngom, G. and Ndoye, M. (2015) Les accidents domestiques chez l'enfant à Dakar: À propos de 555 cas. Journal de Pédiatrie et de Puériculture, 28, 217-222. https://doi.org/10.1016/j.jpp.2015.07.003

[14] Ben Hamida-Nouaili, E., Ben Said, A., Ouzini, F., Bezzine, A., Ben Hamida, A. and Marrakchi, Z. (2011) Epidémiologie des accidents domestiques du jeune enfant à Tunis;impact de la formation des professionnels de la santé sur la qualité de la collecte d'information. la Tunisie Médicale, 89, 766-768.

[15] Ko, A.S., Imbert, P., Diagne, I., Seye, M.N., Gerardini, P., Guyon, P., et al. (2003) Epidémiologie et pronostic des accidents de l'enfant à Dakar, Sénégal. Médecine 
Tropicale, 63, 533-538.

[16] Molinie, E. and Cicurel, J.P. (2008) La sécurité des enfants, que fait-on? Le livre blanc des accidents de la vie courante, 15. Institut National de Consommation, 15-29.

[17] Ategbo, S., Minto'o, S., Koko, J. and Mba-Meyo, S.M. (2012) Aspect épidémiologiques des accidents domestiques de l'enfant à Libreville (Gabon). Clinics in Mother and Child Health, 9, Article ID: C120201. https://doi.org/10.4303/cmch/C120201

[18] Phelah, K.J., Khoury, J., Kalkwarf, H. and Lanphear, B. (2005) Residential Injuries in US Children and Adolescents. Public Health Reports, 120, 63-70. https://doi.org/10.1177/003335490512000111

[19] Ruiz-Casares, M. and Heymann, J.( 2009) Children home alone Unsupervised: Modeling Parental Decisions and Associated Factors in Botswana, Mexico, and Vietnam. Child Abuse \& Neglect, 33, 312-23. https://doi.org/10.1016/j.chiabu.2008.09.010

[20] Reiberg, O., Lutz, N., Reinberg, A. and Mechkouri, M. (2005) Trauma Does Not Happen at Random. Predictable Rhythm Pattern of Injury Occurrence in a Cohort of 15,110 Children. Journal of Pediatric Surgery, 40, 819-825. https://doi.org/10.1016/j.jpedsurg.2005.01.050

[21] Carter, Y.H. and Jones, P.W. (1993) Accidents among Children under 5 Years Old: a General Practice-Based Study in North Staffordshire. British Journal of General Practice, 43, 159-163.

[22] Norberg, E. (2000) Injuries as a Health Problem in Sub-Saharan Africa: Epidemiology and Prospects for Control. East African Medical Journal, 77, S1-S43.

[23] Haggerty, R.J. (1996) Home Accidents in Childhood. Injury Prevention, 2, 290-298. https://doi.org/10.1136/ip.2.4.290

[24] Bahloul, M., Chelly, H., Ben Hmidac, Ksibi, H., Kalleh, H., et al. (2004) Prognosis of Traumatic Head Injury in South Tunisia: A Multivariate Analysis of 437 Cases. The Journal of Trauma, 57, 255-261. https://doi.org/10.1097/01.TA.0000083004.35231.1E

[25] Lavaud, J. and Chouakri, O. (1993) Les accidents domestiques chez l'enfant, Réanimation, soins intensifs. Réanimation, Soins Intensifs, Médecine dUrgence, 9, 110-118. (In French)

[26] WHO Regional Office for Africa (2018) Atlas of African Health Statistics. Universal Health Courage and the Sustainable Development Goals in the WHO African Region. WHO Regional Office for Africa, Brazzaville, Congo.

[27] Munro, S.A., Van Niekerk, A. and Seedat, M. (2006) Childhood Unintentional Injuries: The Perceived Impact of the Environment, Lack of Supervision and Child Characteristics. Child: Care, Health and Development, 32, 269-279.

https://doi.org/10.1111/j.1365-2214.2006.00593.x

[28] Huber, C., Buber-Broun, M.C., Desrentes, M. and Lautier, F. (1987) Acute Petroleum Poisoning in Infants in Gabon (in French). Bulletin de la Société de Pathologie Exotique, 80, 682-688.

[29] Hue, V., Coeugnart-Vanhoucke, J., Dubos, F., Pruvest, I. and Martinot, A. (2011) Accidents de la vie courante observés aux urgences: Absence au échec des moyens de prévention? Archives de Pédiatrie, 18, 1227-1228.

https://doi.org/10.1016/j.arcped.2011.08.001

[30] Jepsen, F. and Ryan, M. (2005) Poisoning in Children. Current Peadiatrics, 15, 563-568. https://doi.org/10.1016/j.cupe.2005.08.006 
[31] Yip, W.L., Ng, H.W., Tse, M.L. and Lae, F.L. (2011) An Epidemiological Study of Paediatric Poisoning in Hong Kong. Hong Kong Journal of Paediatrics, 16, 25-31.

[32] Mercier, C. and Blond, M.H. (1995) Enquête épidémiologique Française sur la brûlure de l'enfant de 0 à 5 ans. Archives de Pédiatrie, 2, 949-956. https://doi.org/10.1016/0929-693X(96)89890-3

[33] Messadi, A., Bousselmi, K., Korbi, A., Chebil, M. and Oueslati, S. (2004) Etude prospective de l'épidémiologie des brûlures de l'enfant en Tunisie. Annals of Burns and Fire Disasters, 17, 173-178.

[34] Foryuoh, S.N., Guyer, B. and Smith, G.S. (1995) Childhood Burns in Ghana: Epidemiological Characteristics and Home-Based Treatment. Burns, 21, 24-28. https://doi.org/10.1016/0305-4179(95)90776-V

[35] Le Dantec, P., Niang, B., Boulesteix, G., Bellefleur, J.P., Pochai, Y. and Dialta, B. (2003) Prise en charge de la brûlure en milieu non spécialisé en Afrique. Médecine Tropicale, 63, 567-572.

[36] Viot, A., Babin, E., Bequignon, A., Moreau, S., Vadivo, M. and VAldazo, A. (2002) Corps étrangers intra-bronchiques de l'enfant. Annales d'Otolaryngologie et deChirurgie Cervicofaciale, 119, 174-180. 